\title{
Dynamically interdependent business model for airline-airport coexistence
}

\author{
Nobuaki MINATO ${ }^{1}$ and Risako MORIMOTO \\ ${ }^{1}$ Graduate School of Technology Management, Ritsumeikan University, Kyoto, Japan \\ ${ }^{2}$ School of Oriental and African Studies, University of London, London, United Kingdom
}

\begin{abstract}
Governments provide various forms of financial support for sustaining unprofitable regional airways, especially when such airways are essential to local livelihoods and economies. However, inefficient provision of subsidies has been subject to worldwide criticism. Therefore, this study examines the load factor guarantee, a dynamically interdependent business model for airline-airport coexistence where an airline and an airport agree on the load factor of a flight, after which either party compensates for any discrepancies between the actual and agreed-upon load factor. The model is calibrated by using 2003-2014 data regarding Noto Airport and All Nippon Airways, and system dynamics are employed to model the dynamic interactions between the two parties. The findings show that successful coexistence between an airline and an airport hinges on the integral management of annual negotiations regarding the target load factor and the monthly demand adjustment of subsidies. In addition, although a subsidy represents a temporary financial loss for an airport, it is an effective way of maintaining long-term, airline-airport coexistence. This model is applicable to unprofitable airways worldwide, and it contributes to their sustainable management.
\end{abstract}

Keywords: Airport, airline, coexistence, system dynamics, load factor guarantee

\section{Introduction}

In general, regional air transportation is characterized by thin air traffic demand with wide fluctuations. Thus, its operational efficiency is lower than that of trunk routes (Suzuki et al., 1995). Critical factors for enhancing the profitability of regional air transportation include fleet selection and daily frequency (Sato et al., 1990). However, at the micro level, air traffic demand forecasts are imprecise (Lyneis, 2000), adding to an airline's difficulties when making decisions and developing new regional airways.

In order to reduce the business risk associated with the entry of a new regional airway, governments provide financial support when air travel demand is expected to be low and air transportation is particularly important to local livelihoods and economies (Minato and Morimoto, 2010, 2011a). Various measures, such as profit loss compensations, landing fee reductions, and fuel tax reductions, are then put in place (Nomura and Kiritoshi, 2010). However, these measures do not essentially mitigate the problem. In addition, anticipated social changes prevent regional air transport systems from solely relying on public financing.

The financial issue becomes more critical when regional air transport systems are not fully supported by governments. For example, in Japan, although air routes to remote islands are subsidized by the central government (Matsumoto, 2007; Minato and Morimoto, 2011b), there are specific conditions in terms of alternative transportation measures and competitions. Moreover, if an airport is not located on an island, it is out of the scope. As a result, the local government that owns the airport must prepare a special financial treatment in order to sustain the airway. However, such subsidies have been criticized in numerous studies, due to their inefficiency (Williams and Pagliari, 2004; Santana, 2009; Grubesic and Matisziw, 2011; Lian and Ronnevik, 2011; Matisziw ${ }^{1}$ and Grubesic, 2012). Thus, introducing a gaming situation between an airline and an airport might improve such inefficiency through interactive decision-making processes.

In this regard, the present paper examines the load factor guarantee (LFG), a dynamically interdependent business model that attempts to share the business risk between an airline and an airport (Figure 1). This model might be able to manage the sustainability of airways, based on market principles in which each player acts for a better payoff in commercial activities. The LFG is an agreement under which an 
airline and an airport (usually owned by a local government in Japan) negotiate the load factor of regional flights beforehand. The airport and government then compensate for any discrepancies between the actual and the agreed-upon load factor. An airline may also transfer a portion of its revenues to a local government when the actual load factor is higher than the guaranteed load factor (Noto Airport Promotion Council (NAPC), 2012). The LFG allows airlines to maintain load factors above the breakeven level, and thus, it encourages them to enter new regional air routes, even when profitability is uncertain. In addition, the owner of the airport, the local government, is encouraged to increase the number of local air passengers in order to enhance the load factor of a regional airway. As a result, a symbiotic relationship between an airline and an airport is established through this business model.

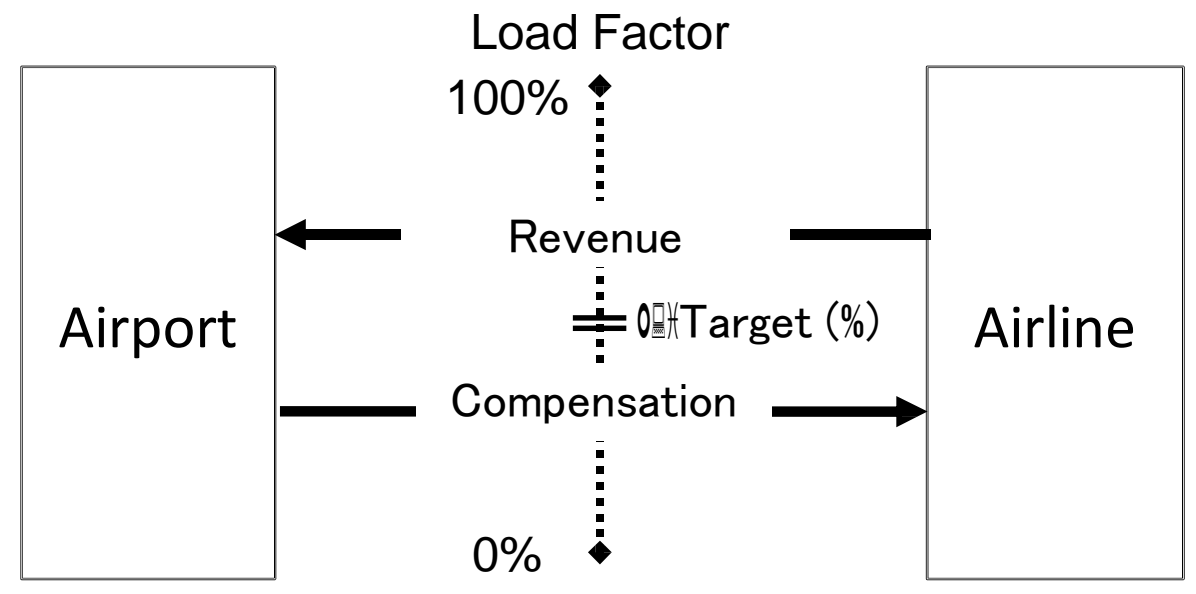

Figure 1. A dynamically interdependent business model between the airline and airport

Many researchers have analyzed the efficiency of the Japanese regional air transport system. Yoshida and Fujimoto (2004) employed data envelope analysis (DEA) to evaluate 67 Japanese airports. Their findings indicate that airports on the Japanese islands are more efficient than those on the mainland. Barros et al. (2010) used the Malmquist input-based index to evaluate 16 Japanese airports operating from 1987 to 2005. They found that the airports (on average) became less efficient and experienced technological regression. Kato et al. (2011) analyzed the financial records of 41 Japanese airports and concluded that the "airports managed by local governments are very difficult to sustain financially without subsidy." In general, 5.2 million passengers are required for airport profitability. However, most Japanese regional airports have fewer than 2.5 million passengers (Kato et al., 2011). Many researchers have concluded that the Japanese air transport system is far from efficient and as a result, measures need to be taken in order to reduce/eliminate such inefficiency.

Inefficiency of regional air transport systems has been discussed worldwide as national subsidy program issues. For example, in the United States, the Essential Air Service (EAS) is a government program that provides a minimum level of air transport service for small communities and connects them through carrier hubs to the national network (Grubesic and Matisziw, 2011). In Europe, the Public Service Obligation (PSO) ensures "minimum" levels of air service to remote areas by subsidizing non-commercial routes (Lian and Ronnevik, 2011). Santana (2009) compared the EAS and the PSO in order to find higher costs for airlines under the PSO program. Grubesic and Matisziw (2011) pointed out that market coverage is often redundant and suggested alternative definitions of "community eligibility" that would increase programmatic efficiency and reduce federal spending on subsidies. Lian and Ronnevik (2011) noted the disadvantages of only providing subsidies for local residents and argued that regional non-residents must pay full fares, which, in turn, restrict the potential for incoming tourism.

Studies have shown two essential trends in managing an unsustainable regional air transport system. The first is the removal of inefficiency from the system in order to realize healthier management. In this regard, researchers tend to evaluate the productivity of airlines and airports as well as promote natural selection through competition. The second trend is the survival of the system depending on resources drawn from outside the system. Based on this approach, various national subsidy programs for airlines and airports can be found worldwide. However, it is important to explore another measure in which each regional air transport stakeholder bilaterally relies on others while coexisting in a market, rather than competing with them 
or being parasitic on public financing. It is expected that the LFG scheme will be one of the measures to achieve the overall objective.

Limited studies have been conducted on the LFG scheme. Hihara (2007) analyzed the LFG agreement between Ishikawa Prefecture and All Nippon Airways (ANA) in Japan. His study attempted to forecast future load factors and pay-offs by considering the impact of the LFG agreement on both parties' decision-making processes. However, the results were not significant, due to the scarcity of data. Fukuyama et al. (2009) analyzed the LFG agreement between Tottori Prefecture in Japan and Korea's Asiana Airlines. Their research considered the LFG as a Nash bargaining competition between the airline and the local government, and examined the rationality of negotiations by using multivariate regression analysis. The negotiations between the two aforementioned parties yielded an approximate Nash bargaining solution in 2007. The abovementioned studies also analyzed the LFG by using mathematical modeling with static data input. However, they did not consider multi-year dynamic interactions between the airline and the airport (Hihara, 2011, 2012), which could significantly affect the future state of the business model.

The purpose of the present paper is to identify key success factors for managing the LFG scheme by analyzing the feedback effect of each party's decision-making process on long-term, airline-airport coexistence. The remainder of the paper is organized as follows. Section 2 explains the methodology used for evaluation, while Section 3 provides an overview of the model structure and describes the results of model building. Section 4 includes the analysis and discussions based on the simulation results. Finally, Section 5 summarizes the conclusions and presents the paper's limitations.

\section{Methodology}

In order to reproduce the LFG scheme, this paper employed system dynamics (SD), which is a method (developed by Jay Forrester of MIT in the 1950s) that models the nonlinear dynamics of complex systems (Sterman, 2000). Stock and flow diagrams (SFDs) use several graphical icons, such as stock, flow, valve, and cloud icons, to express system structures (Figure 2). In addition, stocks are integrated accumulations of inflows and outflows. Inflows are represented by pipes leading into a stock, whereas outflows are represented by pipes leading out of a stock. Valves in the middle of each pipe control the inflows and outflows. Furthermore, clouds represent sources, while flows represent sinks (Sterman, 2000). For mathematical modeling, system dynamism utilizes both integral (Eq. 1) and differential (Eq. 2) equations. Assume that the system state is represented by Stock (t) and calculated as follows:

$$
\operatorname{Stock}(\mathrm{t})=\mathrm{f}_{\mathrm{t} 0}^{\mathrm{t}}[\operatorname{Inflow}(\mathrm{s})-\operatorname{Outflow}(\mathrm{s})] \mathrm{ds}+\operatorname{Stock}(\mathrm{t})
$$

Eq.

where $t_{0}$ is the initial time, $t$ is terminal time, inflow is a connected flow directed toward Stock, and outflow is a connected flow directed away from Stock. The differential of Stock at time $t$ is then calculated asfollows:

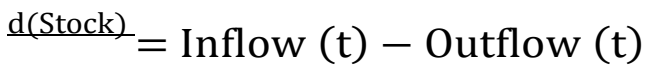

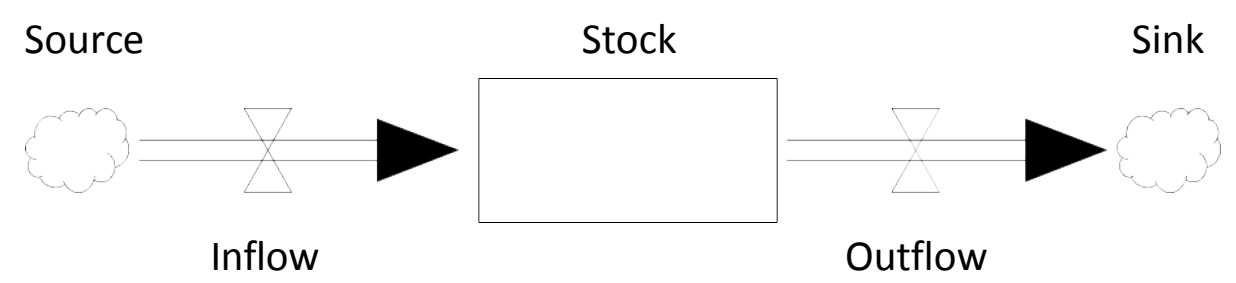

Figure 2. Stock and flow diagram (SFD)

SD assumes rational decisions, which are not always the case in airline-airport negotiations. However, it is useful for understanding macroscopic system behaviors in the long run. Moreover, SD was selected in this paper to integrate two different time scales: 1) annual decisions and 2) monthly decisions. For example, the 
target load factor, a goal for the system, is negotiated between an airline and an airport on an annual basis. It is counted at the end of a year by considering all of the operation results within the year. However, both parties can react to the demand scarcity in a shorter time scale. For example, an airline can control ticket prices daily, weekly, or monthly. Furthermore, an airport can change the amount of subsidies monthly or quarterly. To integrate these different decision time scales, this paper introduced a stock and flow modeling of SD (which represents physical and information flows), based on information feedback controls that are continuously converted into decisions and actions (Suryani et al., 2010). It is assumed that the demand control decisions are made by both parties monthly and the results are accumulated in a stock for deciding the following year's target load factor.

\section{Model development}

\subsection{Model architecture}

The SD model was developed to calibrate a general LFG management framework adopted by an airline and an airport. The model consists of four different subsystems: 1) flight and passenger; 2) demand adjustment; 3) target load factor adjustment; and 4) LFG. Figure 3 presents a subsystem diagram that describes the overall model architecture. The subsystems are presented in the rectangles, while the decision entities (airline and airport) are included in the ovals.

Depending on its flight strategy, an airline provides flights by considering flight frequency and fleet size. The strategy defines supply in terms of the number of seats, while an estimate of the number of passengers is based on historical market demand data. The flight and passenger subsystem generates the annual load factor as an input for the LFG subsystem. The airline and airport negotiate within the load factor adjustment subsystem and generate a target load factor as an input for the LFG subsystem. Payment is computed based on the discrepancy between the annual actual and targeted load factors. When a certain discrepancy exists between the two parties, an airport with financial support from the local government attempts to stimulate passenger demand by providing subsidies. In addition, an airline attempts to control passenger demand by changing the ticket prices. Their reactions bring about demand changes as an input for the LFG subsystem. Thus, airline-airport coexistence is expected to be maintained via the dynamic interaction between the two parties.

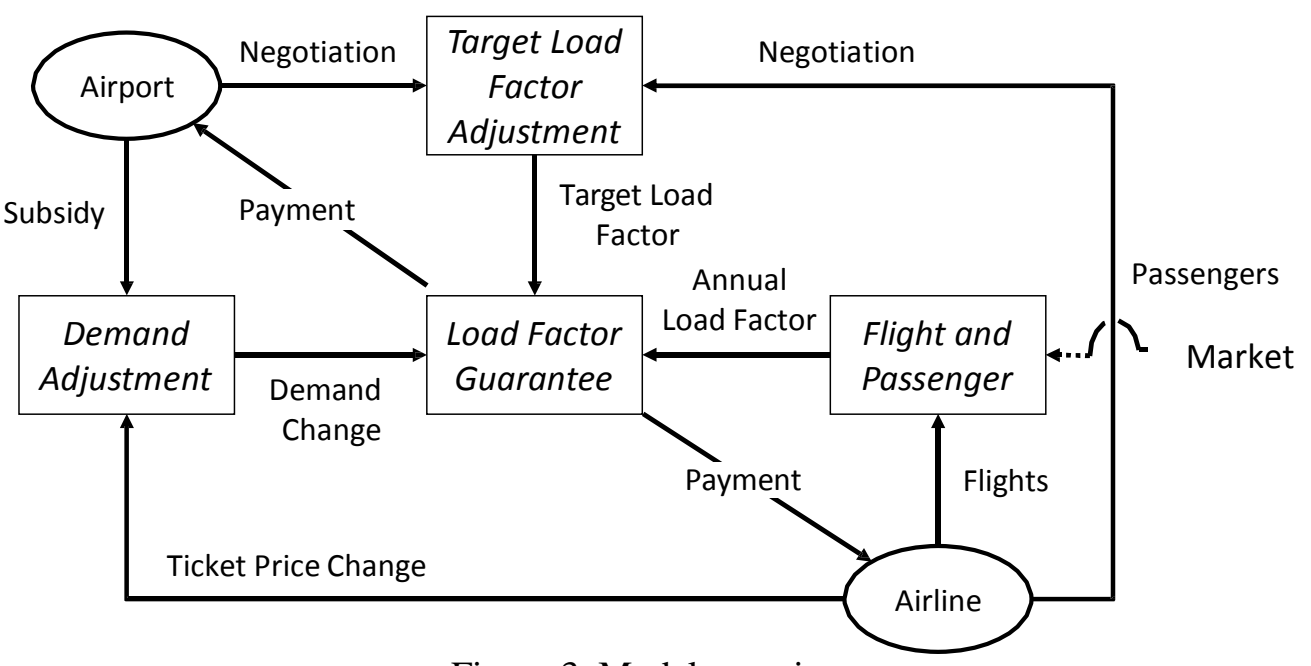

Figure 3. Model overview

\subsection{The flight and passenger subsystem}

Figure 4 shows the SFD of a flight and passenger subsystem. There are two stocks in the model: 1) the accumulated number of seats provided, which generates supply for the system; and 2) the accumulated number of passengers, which generates natural demand for the system. The annual load factor is computed using these two stock variables. Moreover, a stock and flow structure is used to compute the annual load factor in each month by accumulating monthly records.

The monthly number of seats provided, a source of inflow into the stock, is computed as the product of four variables: 1) the number of days per month; 2) the number of flights per day; 3 ) the number of seats per 
aircraft; and 4) operation reliability. Each variable is set based on historical data. The monthly supply is accumulated into the stock for 12 months and it is discarded at the end of a year by using the pulse train function in the Vensim software program.

The other inflow into the stock (i.e., the monthly number of passengers) is computed by totaling monthly passenger demand, subsidized passenger demand, and demand change by price. Monthly passenger demand is a natural demand (based on historical data) calculated by using the lookup function in the Vensim software program. Subsidized passenger demand and demand change by price are computed using the demand adjustment subsystem, which is explained later. Monthly demand is accumulated into the stock for 12 months and discarded at the end of a year. This move might not be practical for air transport business operations. However, the model described herein was designed to simulate the game between an airline and an airport. At the end of each year, they compute the average load factor for the year in order to determine payments to one another, and the result does not influence the following year's passenger demand.

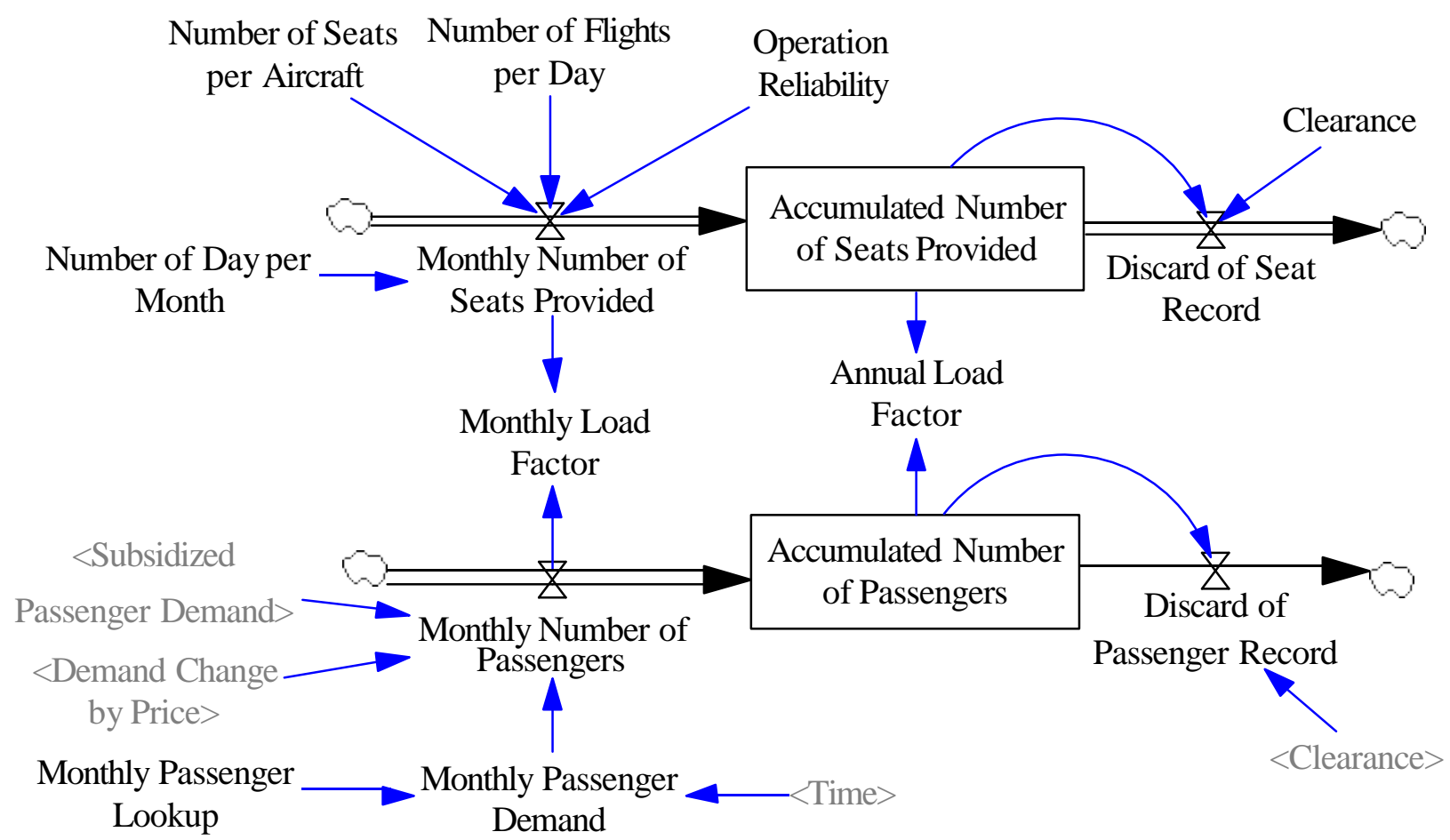

Figure 4. The flight and passenger subsystem

\subsection{The LFG subsystem}

Figure 5 shows the SFD for the LFG subsystem. Two main stocks are used in the model: 1) the financial stock of the airline, calculated by using Eq. 3; and 2) the financial stock of the airport, calculated by using Eq. 4. Here "financial stock" refers to the latest cash position of the airline and the airport. It also facilitates the evaluation of their financial status via the monitoring of these stock variables. "Additional passenger revenues" is calculated by using Eq. 5, while the impact of ticket price change is calculated by using Eq. 6.

An airport pays the guarantee fee, which is calculated by using Eq. 7, when the annual load factor is lower than the target load factor. An airline pays the cooperation fee, which is calculated by using Eq. 8, when the annual load factor is higher than the target load factor. Each payment is calculated at the end of a year, according to clearance.

Financial Stock of Airline

$$
=\text { I Guarantee Fee }- \text { Cooperation Fee + Additional Passenger Revenues }
$$


This is the accepted version of an article published by Elsevier in Journal of Air Transport Management made available under Creative Commons CC-BY-NC-ND 4.0 License Available at: http://dx.doi.org/10.1016/i.jairtraman.2016.08.002

Accepted Version downloaded from SOAS Research Online: http://eprints.soas.ac.uk/23066/

Financial Stock of Airport = I Cooperation Fee - Guarantee Fee - Pay Subsidy

Additional Passenger Revenues

$=$ Average Ticket Price $\times($ Subsidiezed Passenger Demand + Demand Change by Price $)$

Impact of Ticket Price Change $=$ Price Adjustment $\times$ Monthly Passenger Demand

Guarantee Fee $=$ If then else (Target Load Factor

$>$ Annual Load Factor, Accumulated Number of Seats Provided

$1 \times$ Airport Unit Payment $\times$ Clearance, 0 )

$\times$ Discrepancy of Load Factor $\times 2$

Cooperation Fee $=$ If then else (Annual Load Factor

$>$ Target Load Factor, Accumulated Number of Seats Provided

$\times$ Discrepancy of Load Factor $\times 1$

Eq. (8)

$2 \times$ Airline Unit Payment $\times$ Clearance, 0$)$

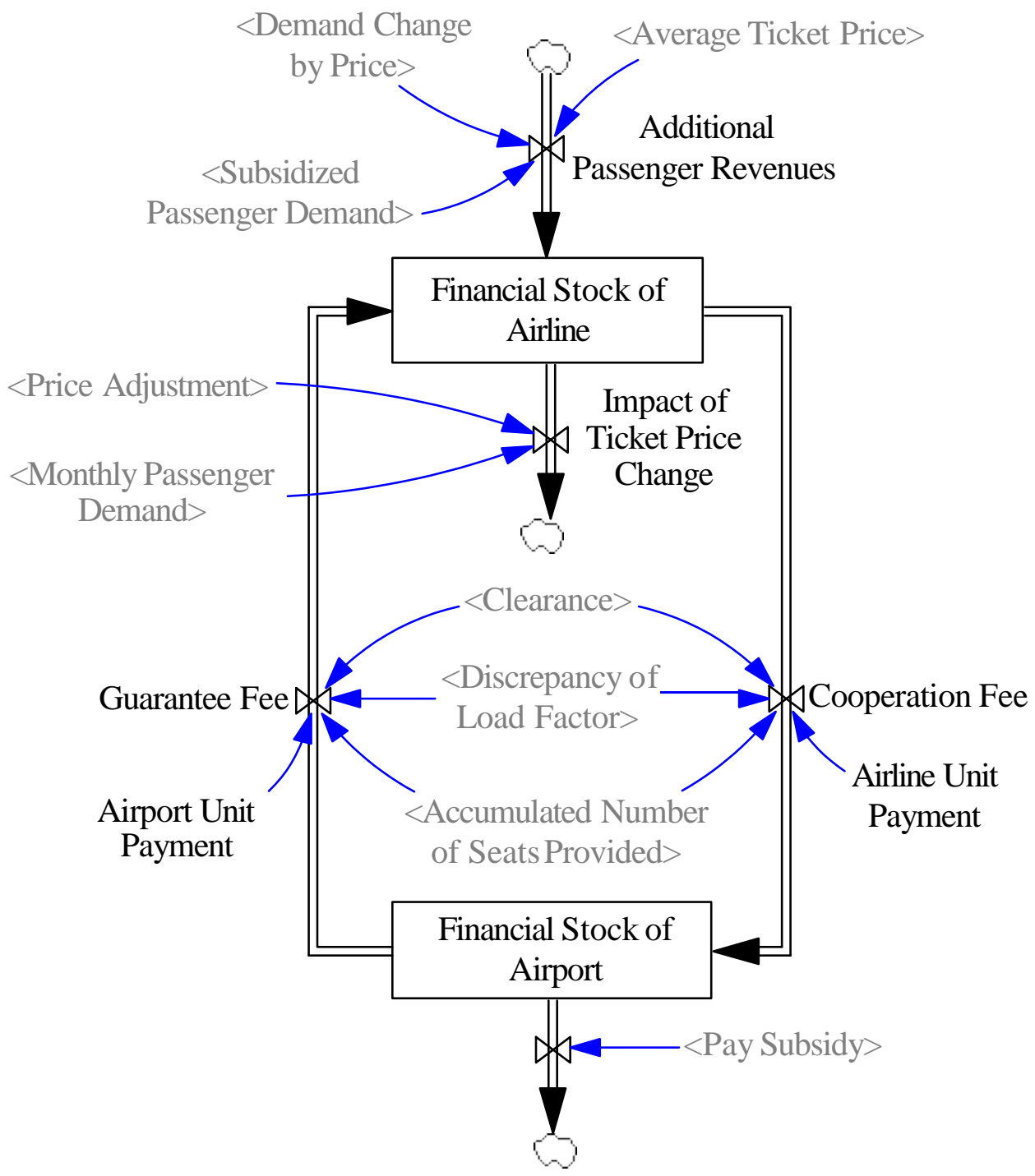

Figure 5. The load factor guarantee subsystem

3.4. The target load factor adjustment subsystem 
Figure 6 shows the SFD of the target load factor adjustment subsystem. The model comprises one stock variable, i.e., the target load factor. Each stakeholder negotiates to adjust the target load factor according to the discrepancy in the load factor. The target load factor increases when the annual load factor is higher than the target load factor of the previous year, whereas it decreases when the annual load factor is lower than the target load factor. The target load factor adjustment rate (TAR) defines the adjusted discrepancy, which serves as the target load factor adjustment.

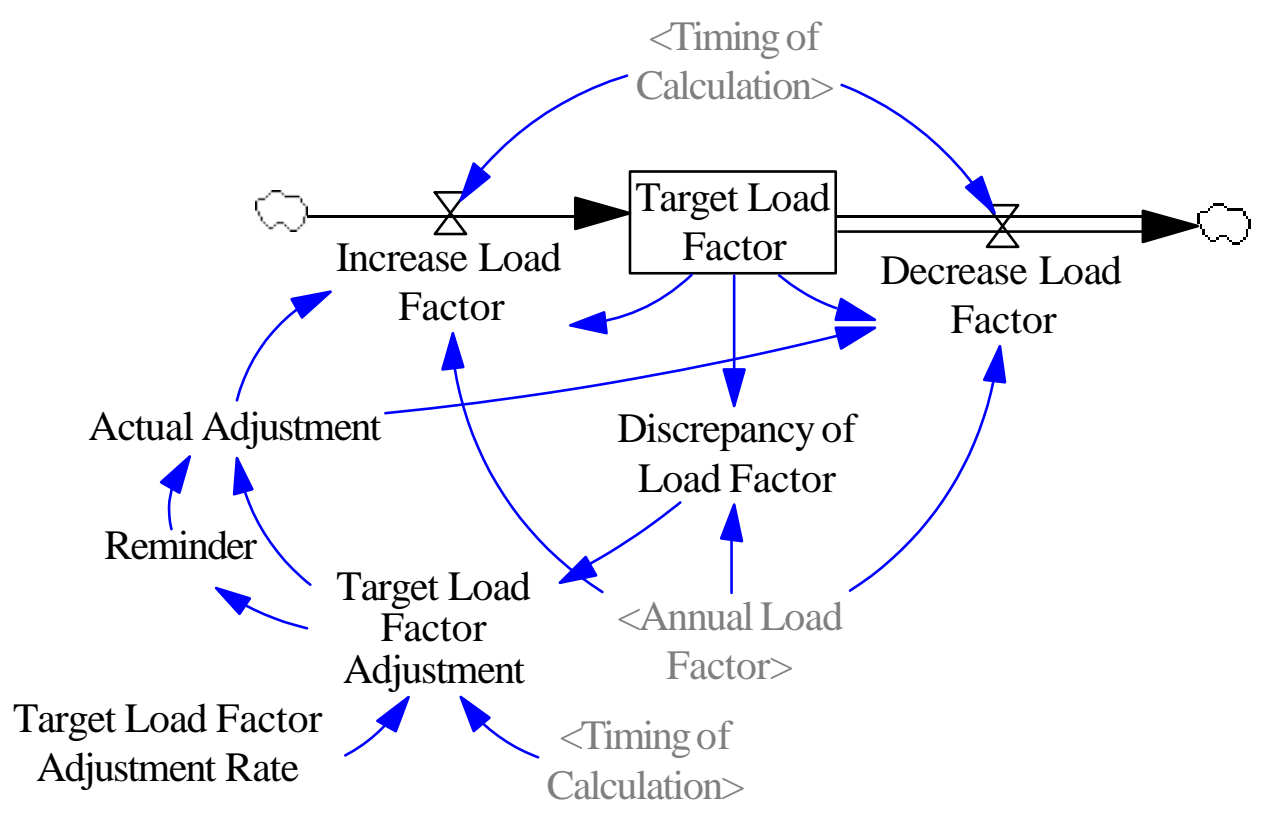

Figure 6. The target load factor adjustment subsystem

3.5. The demand adjustment subsystem

Figure 7 shows the SFD of the demand adjustment subsystem. Demand is adjusted according to the discrepancy between the target load factor and the annual load factor of the previous year and the demand adjustment rate. It is assumed that demand adjustment is based on controlling ticket prices by implementing two different measures; namely, subsidy by airport and price change by airline. Ticket price elasticity of demand is computed by using Eq. 9 (Murakami et al., 2008).

Price Elasticity of Demand $\left(e_{t}\right)=-\underbrace{\left(q_{t+1}-q_{t}\right) / q_{t}}_{t+1} t_{t}^{\left(p_{t}-p\right) / p}$

where $\mathrm{q}$ is demand and $\mathrm{p}$ is price. It is also assumed that price elasticity of demand is fixed throughout the simulation and it is set at -0.74 (Yamauchi, 2000) in the baseline simulation. However, other scenarios can be examined by changing this value.

Regarding the price elasticity coefficient, recent studies have provided different estimations. For example, Mizutani (2011) estimated it as -0.921 , based on 1994-2007 data. However, this estimation was made according to the passenger revenue per passenger-km, which is not the same as the ticket price elasticity coefficient (required for simulation). Moreover, Murakami et al. (2015) estimated it as -0.839 , based on the 14 routes in Japan (from 2 to 11 years). However, the route-specific unbalanced data constraints are valid as coefficients for long-term simulation. Furthermore, Lo et al. (2015) investigated the price elasticities of air cargo demand in Hong Kong and found that it ranges from -0.74 to -0.29 during the 2001-2013 time period. Overall, the price elasticity coefficient depends on industry sectors and countries, and it must be carefully selected according to the simulation purpose. Yamauchi's estimation was conducted as "the long-term price elasticity of air travel in Japan" (2000), and thus, the use of -0.74 is appropriate for the present paper's longterm simulation model development. 
By substituting Eq. 9, the required decrease in ticket price is computed according to Eq. 10, which defines the subsidy per ticket. The total subsidy amount is computed as the product of subsidized passenger demand and subsidy per ticket. The subsidy payment is accumulated in the stock of accumulated amount of subsidy. The amounts that an airport and a local government should spend were evaluated by adjusting the average load factor. It is assumed that an airline proactively changes ticket prices when the demand is insufficient. Considering the expected ticket price in Eq. 11, an airline attempts to fill the price gap between average ticket price and expected ticket price. In addition, price adjustment is computed according to Eq. 12, and demand change by price is computed according to Eq. 13.

Required Decrease in Ticket Price $=-\left(\underline{\left(\mathrm{q}_{\mathrm{t}+1}-\mathrm{q}_{\mathrm{t}}\right) \times \mathrm{p}_{\mathrm{t}}}\right.$

$$
\mathrm{q}_{\mathrm{t}} \times \mathrm{e}_{\mathrm{t}}
$$

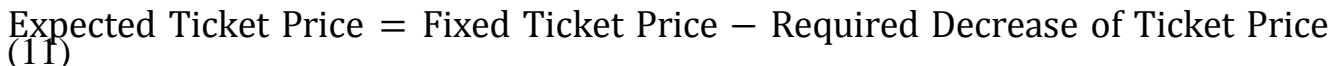

$$
\text { Price Adjustment }=\frac{\text { Price Gap }}{\text { PriceAdjustmentTime }}
$$

Demand Change by Price $=-\frac{\text { Price Adjustment } \times \mathrm{q}_{t} \times \mathrm{e}_{t}}{}$

$\mathrm{p}_{\mathrm{t}}$

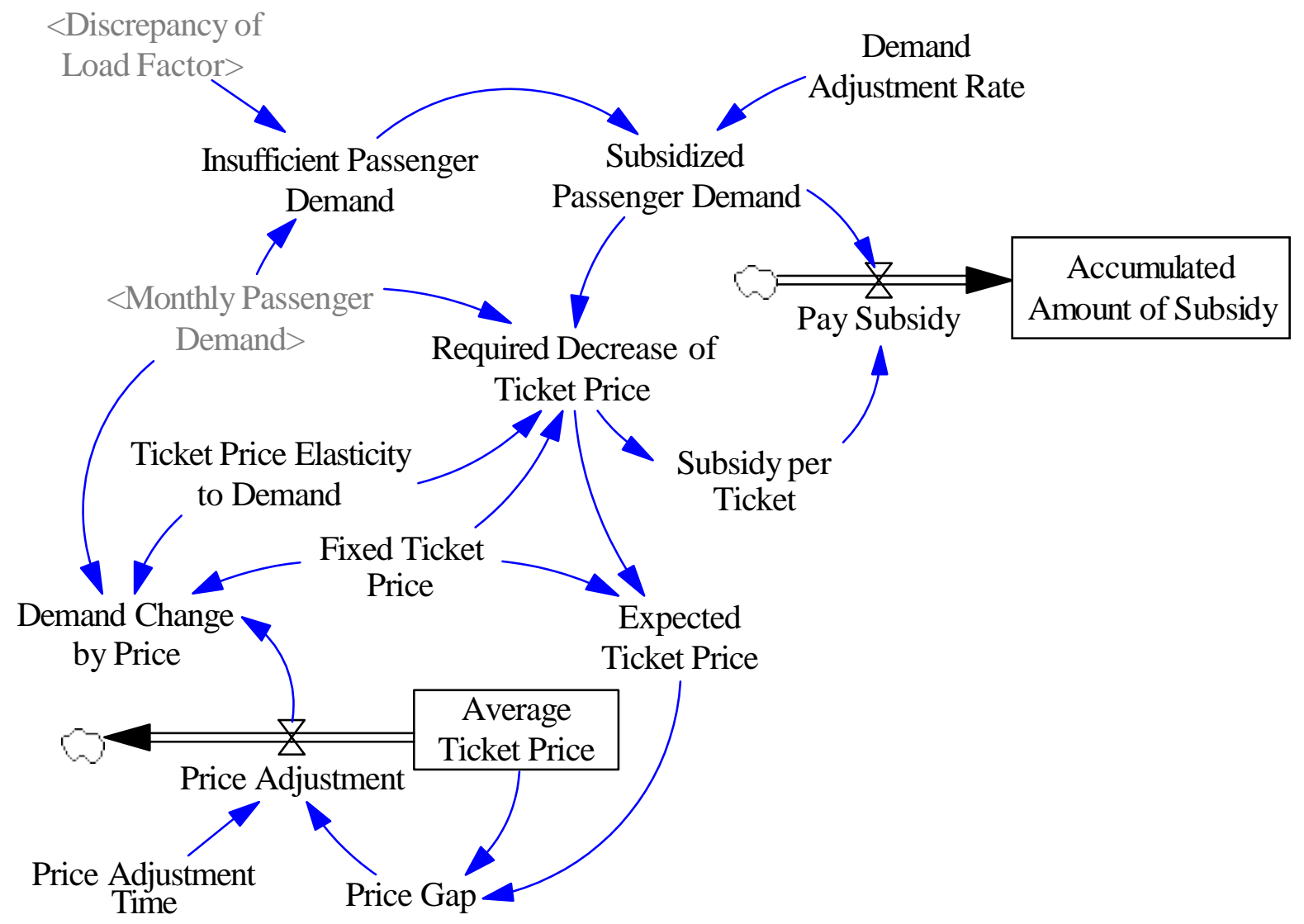

Figure 7. The demand adjustment subsystem

\subsection{Data for model building}

Data regarding the Haneda-Noto flight in Japan was used since it was deemed suitable for the simulation, based on two key reasons. First, the Haneda-Noto route has operated from Noto Airport since it 
This is the accepted version of an article published by Elsevier in Journal of Air Transport Management made available under Creative Commons CC-BY-NC-ND 4.0 License Available at: http://dx.doi.org/10.1016/j.jairtraman.2016.08.002

Accepted Version downloaded from SOAS Research Online: http://eprints.soas.ac.uk/23066/

opened in 2003, thus providing a stream of uninterrupted data. Second, the prefecture government owns and manages the airport, and it has supported ANA and its passengers through an LFG. This particular LFG requires ANA to operate twice-daily flights between Haneda and Noto. Whenever the annual load factors fall below the guaranteed threshold, the prefectural government covers the difference by paying a guarantee fee to ANA. On the other hand, when the load factor exceeds the guaranteed load factor, ANA transfers some revenue (i.e., the cooperation fee) to the prefectural government. These agreements have sustained the twicedaily flights since the airport opened in 2003. The flight and passenger records are presented in the Appendix (NAPC, 2015).

For this particular LFG, both parties have agreed on a maximum payment amount and guaranteed load factor ranges, which have exempted both parties from payments since 2005 (Fukuyama et al., 2009; Minato and Morimoto, 2011b; Hihara, 2012). For example, in 2005, the target load factor was 64\%. In this case, the government was required to only pay ANA when the actual load factor fell below 63\%, while ANA only had to pay the government when the load factor exceeded 65\% (NAPC, 2010). The present model excludes the maximum payment and the guaranteed load factor ranges in order to arrive at a more generalized LFG simulation model.

It is believed that the application of the LFG in the foreign market is technically possible. However, the application of the model requires further surveys regarding various factors such as the country, the airline, the airport, the government, and the community. The parameters for the simulation model must be carefully adjusted according to market conditions. Furthermore, macro-economic factors, socio-geographic factors, and special constraints on a particular country should be investigated for better SD modeling (Minato, 2013). Finally, to facilitate the modeling process, fundamental information in Table 4 is summarized in the Appendix.

\section{7. $\quad$ Model testing}

The model was tested by using historical data regarding the Haneda-Noto flight in 2003 and 2004, since the average load factor in each of those years exceeded the guaranteed load factor and ANA transferred some of its revenue to the prefectural government as a cooperation fee. Thus, it is possible to examine the system's behavior according to the actual reactions of both parties. Two datasets were compared in terms of payment of the cooperation fee or the guarantee fee: Xd (historical data) and Xm (model output). In addition, two measures were used for examining the data fit (i.e., the mean absolute error (MAE) and the mean absolute percentage error (MAPE)) for each item for the two years. Both the MAE and the MAPE provide a measure of the average error between the simulated and actual datasets (Sterman, 2000), even though the MAPE is dimensionless.

Table 1 lists the model testing results. Regarding the guarantee fee, the simulation results are identical to the historical data regarding both 2003 and 2004. The model succeeded in reproducing past behaviors. Regarding the cooperation fee, there were cash transfers from ANA to Ishikawa Prefecture in both 2003 and 2004. The actual amount transferred in 2003 was 811,000 USD and the simulation result was 811,562 USD (a deviation of only 562 USD). In 2004, the actual amount paid was 133,167 USD, while the simulation result was 136,766 USD (a deviation of only 3,599 USD). Furthermore, the MAE was 2,081 USD, while the MAPE was $1.4 \%$. The simulated cooperation fee payout deviated slightly from the historical data, but it is opined that the model can appropriately reproduce macroscopic system behaviors for further simulation.

Table 1. Model testing results

\begin{tabular}{|c|c|c|c|c|c|}
\hline \\
\hline & & 2003 & 2004 & MAE & MAPE \\
\hline \multirow{2}{*}{ Cooperation Fee (USD) } & $\mathrm{Xd}$ & 811,000 & 133,167 & \multirow{2}{*}{2,081} & \multirow{2}{*}{$1.4 \%$} \\
\hline & $\mathrm{Xm}$ & 811,562 & 136,766 & & \\
\hline \multirow{2}{*}{ Guarantee Fee (USD) } & $\mathrm{Xd}$ & 0 & 0 & \multirow{2}{*}{0} & \multirow{2}{*}{$0.0 \%$} \\
\hline & $\mathrm{Xm}$ & 0 & 0 & & \\
\hline
\end{tabular}

\section{Results and discussions}

In this paper, four different scenarios were examined: 1) baseline; 2) target load factor adjustment; 3) demand adjustment; and 4) combination. The baseline scenario does not include any measure of impact on the system. The target load factor adjustment scenario includes an adjustment to the rate of the guaranteed load factor. The demand adjustment scenario consists of a demand adjustment using ticket subsidies and price 
change, while the combination scenario includes both target load factor adjustment and demand adjustment. For each scenario, the simulation was run for 120 months (10 years). The simulation period was identical to the period of flight operation (2005-2014) for which the time-series monthly demand data was acquired (see the Appendix).

\subsection{The baseline scenario}

The baseline scenario was set assuming no target load factor adjustment or demand adjustment. Figure 8 shows the financial stocks of the airline and the airport. The movements of each financial stock are horizontally symmetrical to the even level since neither party undertook any adjustment actions. The difference between the airline and the airport can be explained by the results of the guarantee fee and the cooperation fee (Figure 9). Initially, the airline continuously paid the cooperation fee to the airport since there was adequate air passenger demand. The amount of these payments gradually decreased over time due to a decrease in passenger demand. However, the trend began to change around the fifth year, due to decreased passenger demand. As a result, the airport had to pay the guarantee fee to the airline in order to cover the discrepancy in the load factor. Figure 9 shows that both parties win and lose at various times. Thus, the airline-airport relationship is not a path-dependent system, implying that the payment amounts will probably be balanced over the long term, according to demand movement. However, it must be highlighted that the airline temporarily bore the negative financial situation over the entire simulation period. This situation might force the airline to cease commercial operations on the selected route. Based on these findings, it is concluded that the airway is not likely to be sustainable under the baseline scenario. This paper then examined a certain measure for enhancing airline-airport coexistence.

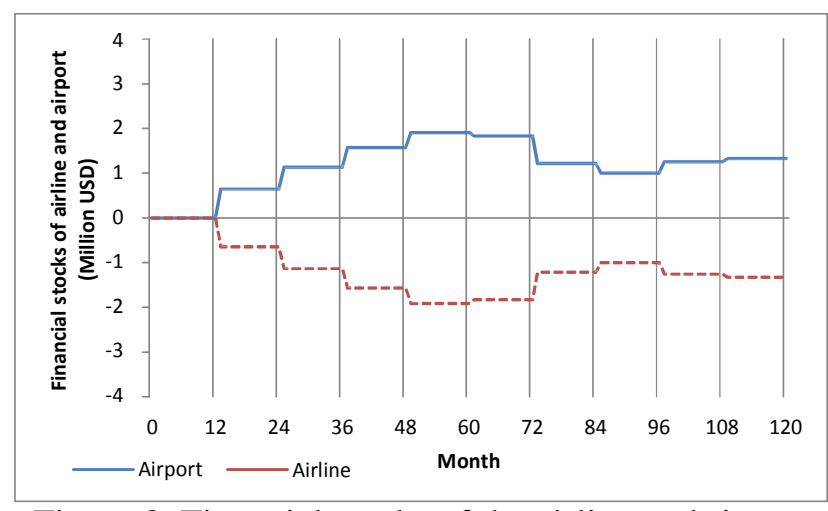

Figure 8. Financial stocks of the airline and airport (baseline scenario)

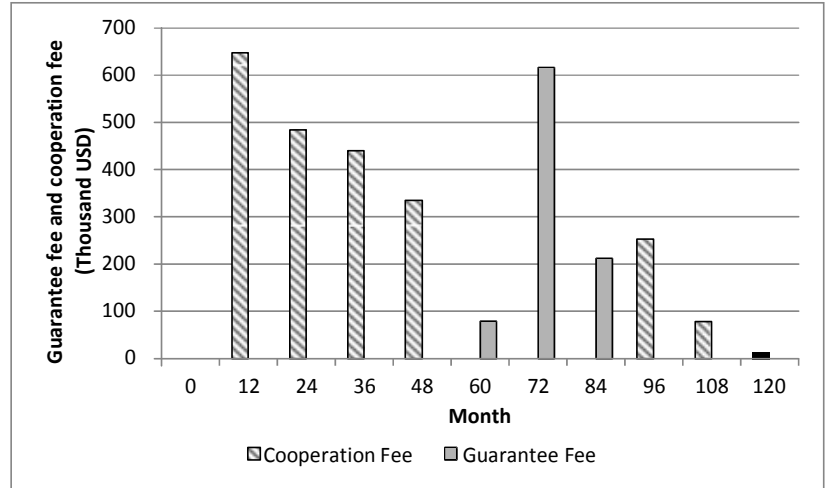

Figure 9. Guarantee fee and cooperation fee (baseline scenario)

\subsection{The target load factor adjustment scenario}

The target load factor adjustment scenario was examined by highlighting the target load factor adjustment subsystem. It is assumed that both parties negotiate to adjust the target load factor, according tothe load factor discrepancy in the previous year. Then, a parametric study was implemented on the target load factor adjustment rate (TAR), setting it to $25 \%, 50 \%, 75 \%$, and $100 \%$, without any adjustment to the demand side.

Figures 10a-d show the financial stocks of the airline and the airport under the target load factor adjustment scenarios. At 25\% TAR (Figure 10a), the discrepancy between the two parties is smaller than that in the baseline scenario (Figure 8) in the first six years. This implies that the load factor adjustment positively affects sustainability. However, the time-series behaviors changed after the seventh year. The airline continuously accumulated cash into its stock, while the airport continuously lost cash from its stock. This discrepancy in financial stocks generally increased over time, implying that load factor adjustment negatively impacted sustainability. At 50\% TAR (Figure 10b), the global trend in time-series behaviors is the same as that at 25\% TAR. However, there is less discrepancy between the two parties. This finding implies that the situation is more favorable for the airline and the airport, especially from the viewpoint of sustaining their commercial relationship. Furthermore, at 75\% TAR (Figure 10c), the global trend in the time-series behaviors is the same as that at 25\% TAR and 50\% TAR. However, there is much less discrepancy between the two 
This is the accepted version of an article published by Elsevier in Journal of Air Transport Management made available under Creative Commons CCBY-NC-ND 4.0 License Available at: http://dx.doi.org/10.1016/j.jairtraman.2016.08.002

Accepted Version downloaded from SOAS Research Online: http://eprints.soas.ac.uk/23066/

parties. This result indicates that, as TAR increases, the discrepancy between the financial stocks of the two parties also decreases. At 100\% TAR (Figure 10d), the financial stocks remain at approximately zero for both parties. Based on these findings, it can be concluded that TAR is suitable for maintaining financial equality between an airline and an airport.

In addition, symmetry was found according to the even level among all of the time-series behaviors in Figures $10 \mathrm{a}-\mathrm{d}$. When the result is positive for the airline, the result is always negative for the airport, and vice versa. The movements are also totally symmetrical, meaning that load factor adjustment was satisfactory for improving the benefit to the airline, while simultaneously decreasing the benefit to the airport. Thus, an appropriate trade-off must be designed between the airline and the airport for the sake of long-term coexistence. Moreover, introducing load factor adjustment can change the time-series behaviors, but it cannot break the symmetry to an even level.

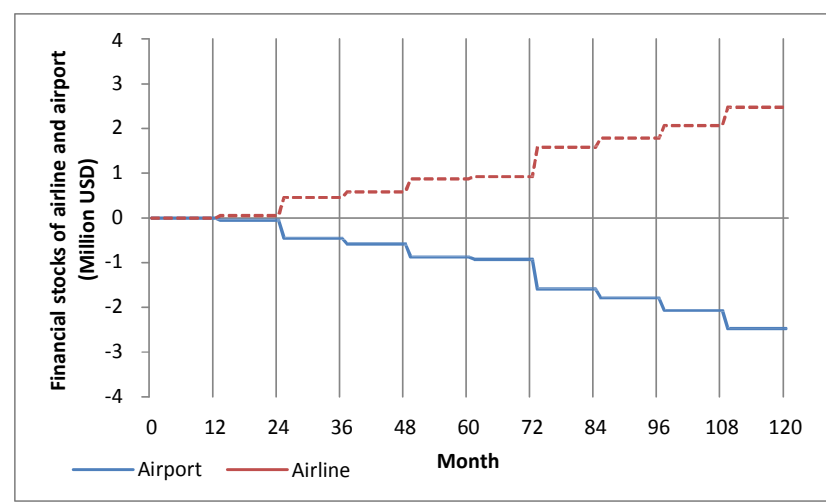

Figure 10a. Financial stocks of the airline and airport $(\mathrm{TAR}=25 \%)$

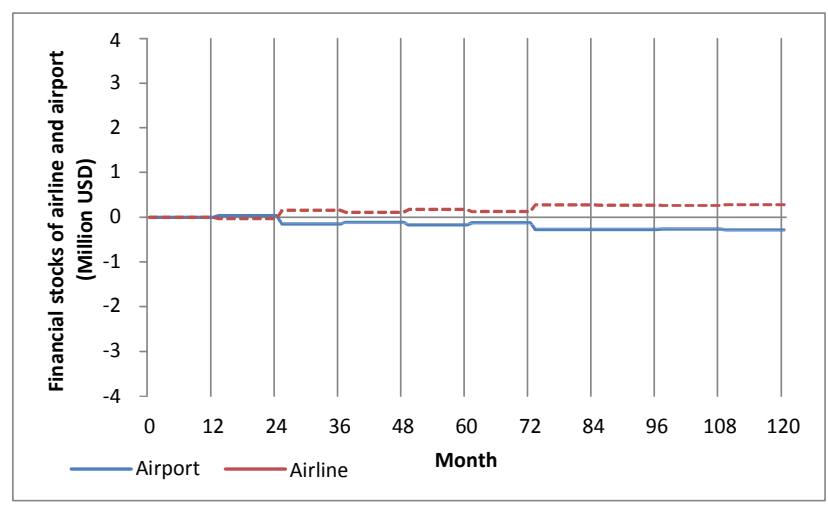

Figure 10c. Financial stocks of the airline and airport $(\mathrm{TAR}=75 \%)$

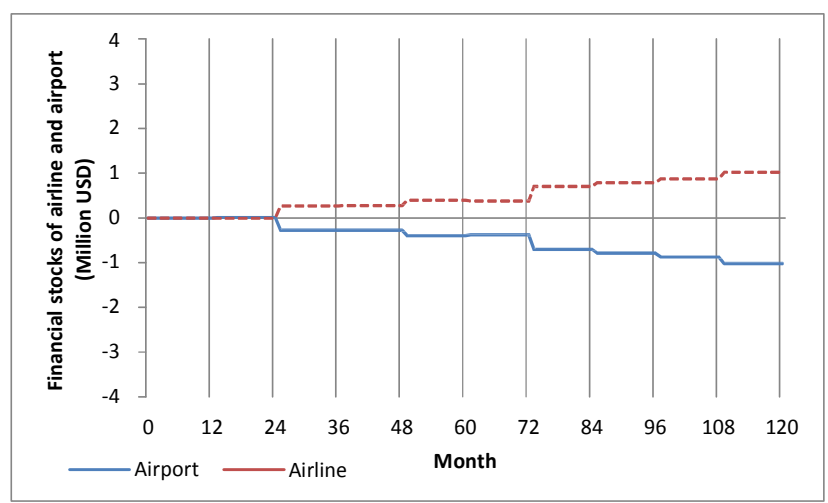

Figure 10b. Financial stocks of the airline and airport $(\mathrm{TAR}=50 \%)$

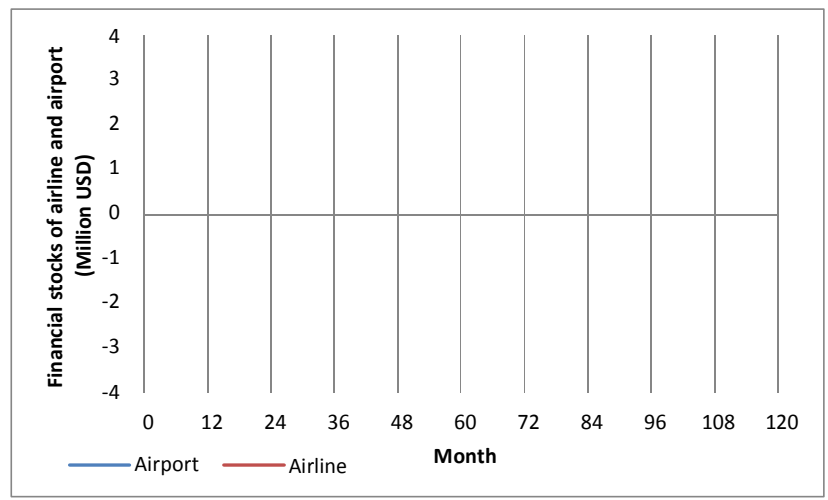

Figure 10d. Financial stocks of the airline and airport $(\mathrm{TAR}=100 \%)$

\subsection{The demand adjustment scenario}

The demand adjustment scenario was examined by highlighting the demand adjustment subsystem. It is assumed that an airport increases the number of air passengers in the case of certain discrepancies in the load factor. In this simulation, the airport increased demand by using ticket subsidy and assuming financial support from the local government that owned the airport, based on a discrepancy in the load factor of the previous month.

The model includes the impact of subsidy payment and demand increase on both parties. Subsidy payment was subtracted from the financial stock of the airport since the subsidy requires the airport to bear some expenditure. In contrast, additional revenues are expected for the airline since the number of air passengers increased, due to the subsidy effect. Additional passenger revenue was computed as the product of subsidized passenger demand and average ticket price. A parametric study was implemented on the demand adjustment rate (DAR), setting it to $25 \%, 50 \%, 75 \%$, and $100 \%$, without any adjustment to the loadfactor. 
Figures 11a-d show the financial stocks of the airline and airport under the demand adjustment scenarios. There were no clear distinctions among the figures. However, a slight improvement was found in the financial stocks of both parties, especially after comparing them with the baseline (Figure 8). At 25\% DAR (Figure 11a), no distinction was found between the demand adjustment scenario and the baseline scenario (Figure 8) during the first five years, indicating that demand adjustment was inactive since air passenger demand was adequate. After the sixth year, the demand adjustment was activated due to inadequate demand. At 50\% DAR (Figure 11b), clearer improvements could be seen in the financial stocks of both parties after the fifth year, and the trend was the same as those at 75\% DAR and 100\% DAR. The results imply that introducing demand adjustment can positively impact both parties, given an appropriate DAR based on demand scarcity.

In principle, it is expected that the higher the DAR, the higher the expenditures from the airport, meaning that the airport's financial state worsens by the increased DAR. Interestingly, however, the airport's financial state also improves with the increased DAR. This finding is based on the feedback effect of subsidized passenger demand, which contributes to an increase in the average load factor, which, in turn, decreases the guarantee fee paid by the airport.

In all of the demand adjustment scenarios (Figures 11a-d), the financial stocks improved toward the end, due to additional (generated) demand. Furthermore, one party's improvement was not realized at the cost of the other party. This finding implies that both an airline and an airport are likely to be satisfied with the business model, and thus, airline-airport coexistence can be sustained.

It is concluded that introducing a monthly demand adjustment, as in the simulation, can break the symmetry to an even level for both parties, thus contributing to a more favorable commercial airway operation design. However, the demand adjustment in this simulation does not appear to lessen the discrepancy between the financial states of the two parties. This finding implies that financial equality between an airline and an airport cannot be balanced over the long term by the demand adjustment system. Therefore, this paper explores the possibility of combining both the TAR and the DAR in one scenario.

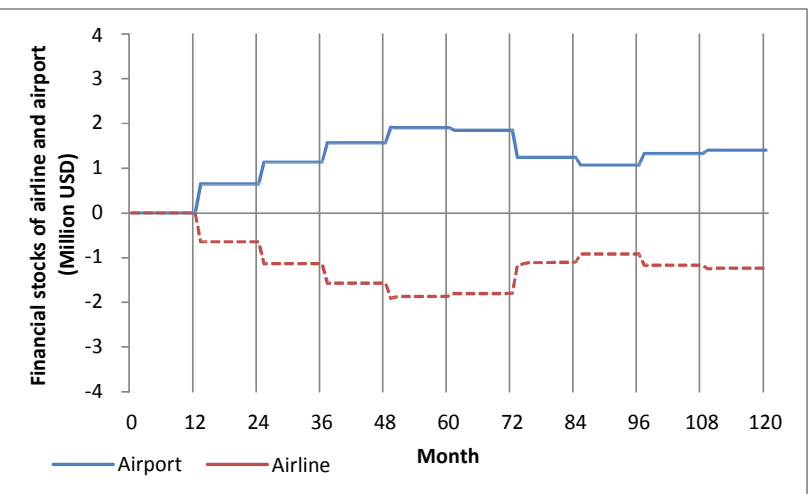

Figure 11a. Financial stocks of the airline and airport $($ DAR $=25 \%)$

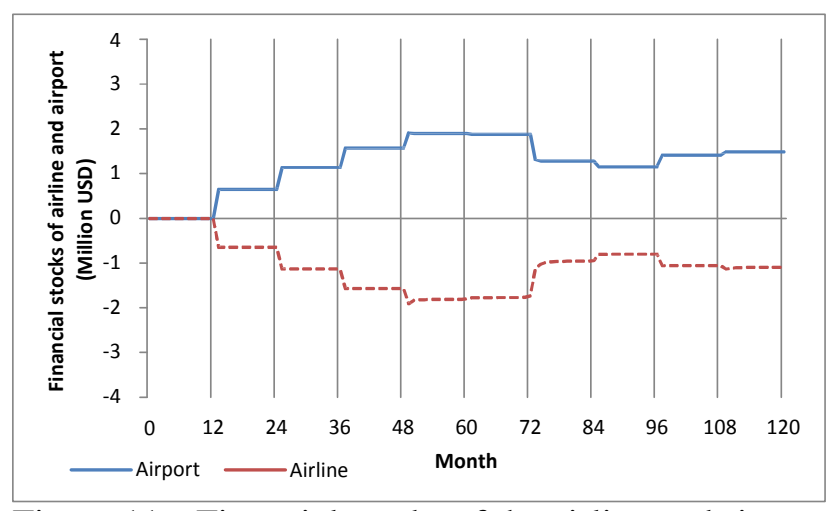

Figure 11c. Financial stocks of the airline and airport $(\mathrm{DAR}=75 \%)$

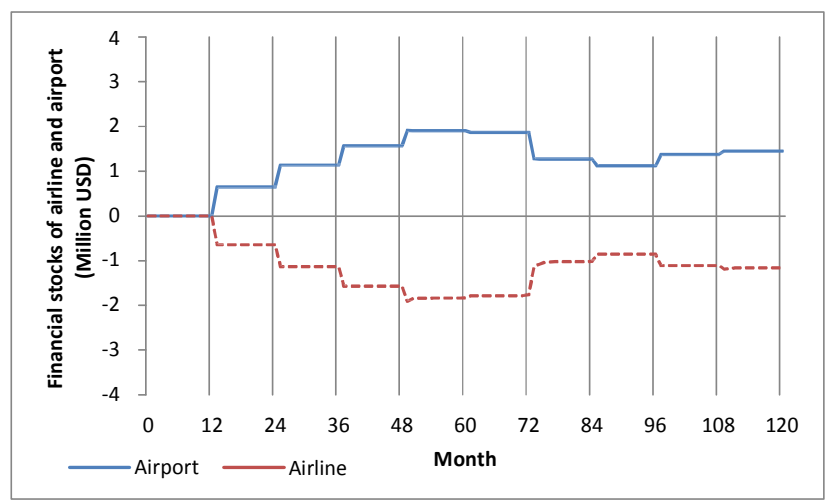

Figure 11b. Financial stocks of the airline and airport $(\mathrm{DAR}=50 \%)$

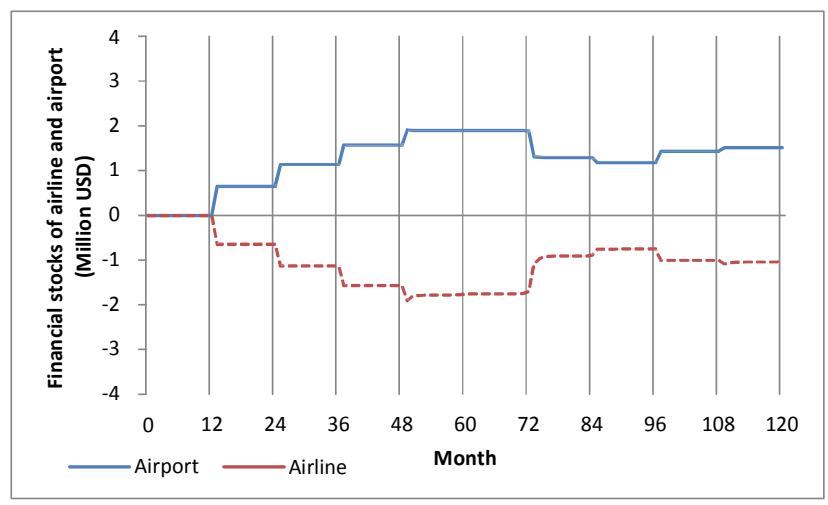

Figure 11d. Financial stocks of the airline and airport $(\mathrm{DAR}=100 \%)$ 
This is the accepted version of an article published by Elsevier in Journal of Air Transport Management made available under Creative Commons CC-BY-NC-ND 4.0 License Available at: http://dx.doi.org/10.1016/j.jairtraman.2016.08.002

Accepted Version downloaded from SOAS Research Online: http://eprints.soas.ac.uk/23066/

\subsection{The combination scenario}

The combination scenario was examined by highlighting both the target load factor adjustment subsystem and the demand adjustment subsystem. In addition, a parametric study was implemented on the TAR, setting it to $25 \%, 50 \%, 75 \%$, and $100 \%$ as well as on the DAR, setting it to $25 \%, 50 \%, 75 \%$, and $100 \%$.

Figures 12a-d show the financial stocks of the airline and the airport under the combination scenarios. When both the TAR and DAR were set to 25\% (Figure 12a), the result was similar to that at 25\% TAR

(Figure 10a). The discrepancy between the two parties gradually increased throughout the simulation. Symmetry regarding the even level was broken, but the break was not distinctive. Thus, at 25\%, the TAR has a greater influence on the system than the DAR. When both the TAR and DAR was set to $50 \%$ (Figure 12b), the discrepancy between the two parties decreased, compared to that in the case of 25\% (Figure 12a). Furthermore, the financial states of both the airline and the airport improved. Symmetry regarding the even level was totally broken. The same trends were found in the cases of 75\% (Figure 12c) and 100\% (Figure 12d).

As discussed earlier, the TAR can decrease the discrepancy in the financial states of an airline and an airport. Conversely, the DAR can break the symmetry and improve both parties' financial states. Thus, a similar behavior was expected as that of the load factor adjustment scenarios (Figures 10a-d), with a certain positive shift due to demand adjustment. However, the simulation result was contrary to such an expectation, indicating that there is an effect of further demand generation resulting from the combination. The additional effect can be explained by the interaction between target load factor adjustment and demand adjustment. In this model, demand adjustment can generate additional demand until the annual average load factor reaches the target load factor. Given that the target load factor is fixed, the load factor adjustment only prevents deterioration in the financial state of the airport. In other words, an airport's reaction is limited to minimizing the amount of loss, especially when a certain loss is expected at the end of each year. The only concern for the airport is the discrepancy between the target and the average load factors. There is no incentive for an airport to go beyond the target load factor.

However, introduction of the load factor adjustment removes this limitation. Since the target load factor changes on an annual basis, an airport must take care to meet an airline's expectation. Given that an airport's endeavor is only limited to filling the discrepancy between the target and the average load factors, the target load factor continuously decreases until the airline decides to cease the flight operation. Thus, there is a clear incentive for an airport to go beyond the target load factor for sustaining the airway. Furthermore, there is another incentive for an airport; that is, receiving cooperation fees from an airline. The cooperation fees contribute toward compensating for subsidy expenditures. This is why the airport proactively pays higher subsidies to go beyond the target load factor, especially under the combination scenarios.

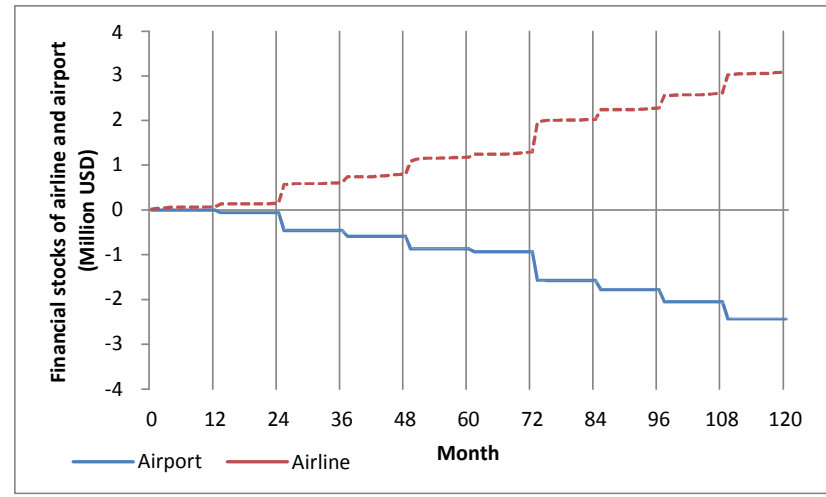

Figure 12a. Financial stocks of the airline and airport $(\mathrm{TAR}=25 \%, \mathrm{DAR}=25 \%)$

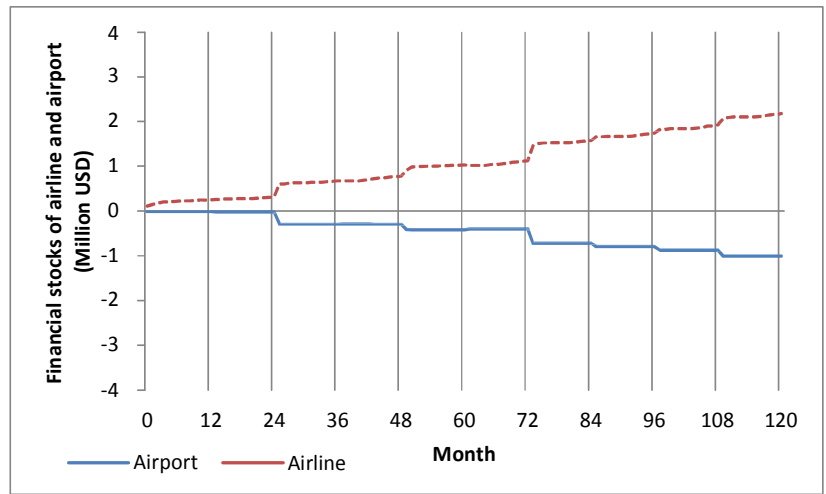

Figure 12b. Financial stocks of the airline and airport $(\mathrm{TAR}=50 \%, \mathrm{DAR}=50 \%)$ 


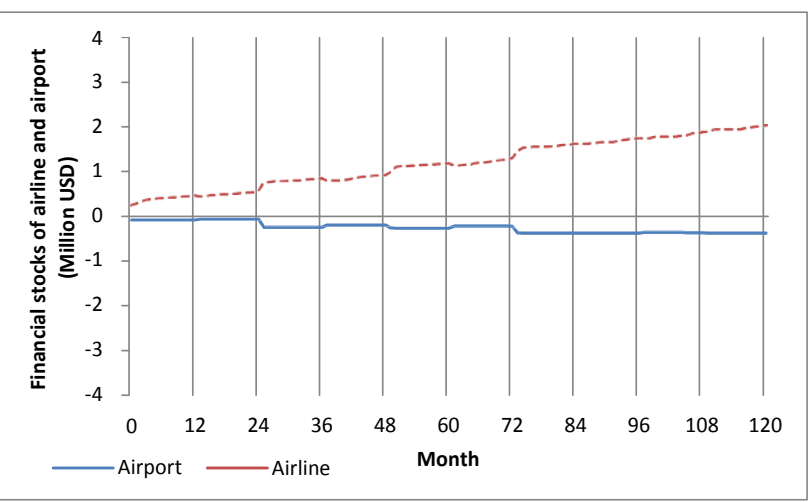

Figure 12c. Financial stocks of the airline and airport $(\mathrm{TAR}=75 \%, \mathrm{DAR}=75 \%)$

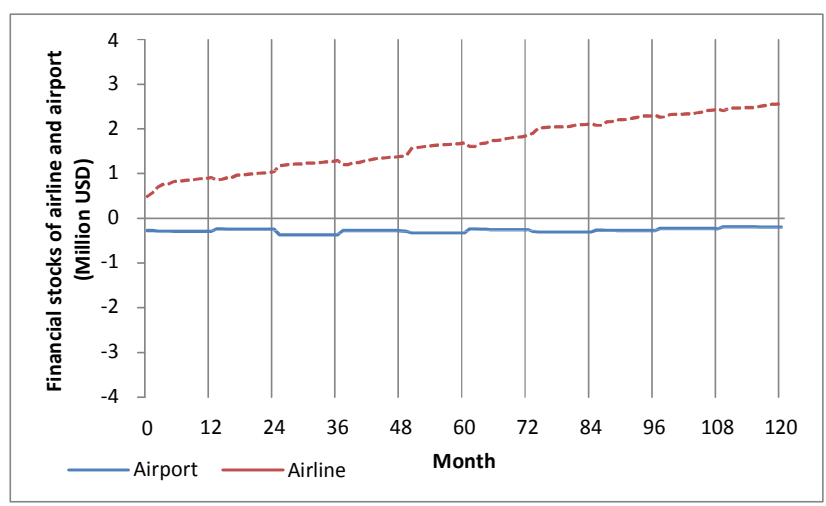

Figure 12d. Financial stocks of the airline and airport $(\mathrm{TAR}=100 \%, \mathrm{DAR}=100 \%)$

\section{Conclusions}

This paper used system dynamics to examine an interdependent business model (i.e., the LFG) for airline-airport coexistence. According to this model, an airline and an airport agree on the load factor of a flight and either party compensates for any discrepancy between the actual and agreed-upon load factors. The simulation results show that adjustments to the load factor can decrease any discrepancies between the financial states of an airline and an airport. However, it cannot break the symmetry of both parties' financial states. Conversely, adjustments to the demand can break the symmetry, but they cannot lessen the discrepancy. Thus, it is concluded that integrating load factor adjustment and monthly demand adjustment is the key to successful airline-airport coexistence. Although integration of a subsidy with an LFG means a temporary financial loss for the airport, research indicates that such a measure is effective for long-term airline-airport coexistence.

However, current management practices are contrary to the findings of this paper. These practices only involve introducing the LFG to reduce business risk to an airline when pursuing a new entry. In Japan, most local governments provide subsidies to maintain unprofitable regional flights. However, such a subsidy policy is not optimally integrated with the LFG. Under the competitive environment, especially after deregulation, airports and airlines need to work together to improve and develop close partnerships (Graham, 2003). The proposed SD model can help airports and airlines better understand the interdependency of their businesses and how cooperation can enhance business sustainability.

Finally, the present paper focused on the most fundamental actions and reactions by an airline and an airport. However, it is important to simulate various scenarios in order to study the interactions between the two parties. For example, future studies should vary the amount of the subsidy, compensation fee, and cooperation fee to better understand various system behaviors. In addition, this paper employed one performance measure of the load factor in the simulation. Thus, introducing multiple performance measures, such as traffic volumes and profit margins, can be more effective.

\section{Acknowledgements}

This research was first presented at the International Conference of System Dynamics (ISD2012) in St. Galen, Switzerland (July 2012), after which it was modified based on the comments received and the data acquired at the conference. The model was further improved for presentation at the International Forum of Ship, Ports, and Airports (IFSPA 2015). We would like to thank all of those at the conferences who provided their insightful comments. We also would like to thank the editors and the anonymous journal reviewers for their helpful suggestions. This paper was supported by JSPS KAKENHI Grant Nos. 5870720 and 15K17124.

\section{References}

Barros, C., Managi, S., Yoshida, Y. 2010. Productivity growth and biased technological change in Japanese airports. Trans. Policy. 17 (4), 259-265. 
This is the accepted version of an article published by Elsevier in Journal of Air Transport Management made available under Creative Commons CC-BY-NC-ND 4.0 License Available at: http://dx.doi.org/10.1016/j.jairtraman.2016.08.002

Accepted Version downloaded from SOAS Research Online: http://eprints.soas.ac.uk/23066/

Fukuyama, T., Kagawa, T., Ikeda, Y., 2009. Analyses on international airways at Yonago Airport in Japan: Benefit and bargaining of local government. IATSS Rev. 34(1), 90-98.

Graham, A., 2003. Managing Airport: An International Perspective, second ed. Oxford, U.K.: Elsevier, 8, 203-216.

Grubesic, T., Matisziw, T., 2011. A spatial analysis of air transport access and the essential air service program in the United States. J. Trans. Geography. 19 (1), 93-105.

Hihara, K., 2007. Quantitative analysis about the payoffs of "Load Factor Guarantee Mechanism" for Noto Airport. J. Japanese Society of Transport Economics. 51, 169-178.

Hihara, K. 2011. An Analysis on Airport-Airline Vertical Relationships with Risk Sharing Contracts under Asymmetric Information Structures. Procedia - Soc. and Behavioral Sci. 20, 1090-1098.

Hihara, K. 2012. An analysis of an airport-airline relationship under a risk sharing contract. Trans. Res Part E: Logist and Transp Rev. 48 (5), 978-992.

Lian, J., Ronnevik, J., 2011. Airport competition—Regional airports losing ground to main airports. J Trans. Geography. 19 (1), 85-92.

Lo, W., Wan, Y. Zhang, A. 2015. Empirical estimation of price and income elasticities of air cargo demand: The case of Hong Kong. Transp. Res. Part A: Policy and Practice. 78, 309-324.

Matisziw, T., Lee, C., Grubesic, T., 2012. An analysis of essential air service structure and performance. J. Air Trans. Management. 18 (1), 5-11.

Matsumoto, I., 2007. A Study of the Air Routes and the Airports in 5 isolated Islands in Nagasaki. Nagasaki Prefectural University J. 41 (3), 111-186.

Minato, N., Morimoto, R., 2010. Sustainable airline strategy using portfolio theory. J. Air Trans. and Management. 17(3), 195-198.

Minato, N., Morimoto, R., 2011a. Designing commercial sustainability of unprofitable regional airport using system dynamics analysis. Res. in Trans. Bus. and Management. 1(1), 80-90.

Minato, N., Morimoto, R., 2011b. Policy design for sustainable regional air transport using load factor guarantee. Japanese J. Sys. Dyn. 10, 13-24.

Minato, N., Morimoto, R., 2012. System dynamics analysis on a management of airline-airport coexistence with a load factor guarantee. Proceedings of International System Dynamics Conference 2012. St. Gallen, Switzerland.

Mizutani, J. 2011. Airline merger and competition in Japan: A conduct parameter and theoretical price approach. J. Air Trans. Management. 17 (2), 120-124.

Murakami, H., Amano, Y., Asahi, R. 2015. Dynamic effect of inter-firm rivalry on airfares: Case of Japan's full-service and new air carriers. J. Air Trans. Management. 44-45, 25-33.

Nomura, S., Kiritooshi, K., 2010. Aviation globalization and airport business. Doubun-kan, Japan. 89-98, 160-161.

Noto Airport Promotion Council (NAPC). 2012. http://www.noto-airport.jp/(accessed 09.09.15).

Santana, I., 2009. Do public service obligations hamper the cost competitiveness of regional airlines? J. Air Trans. Management, 15(6), 344-349.

Sato, K., Takano, N., Igarashi, H., 1990. Introduction program of regional air transportation. Proceedings of Operation Research Society of Japan. Spring.

Sterman, J., 2000. Business Dynamics: Systems Thinking and Modelling for a Complex World. McGraw Hill Higher Education, USA. 192, 229.

Suryani, E., Chou, S., Chen, C., 2010. Air passenger demand forecasting and passenger terminal capacity expansion: A system dynamics framework. Expert Sys. with Applications. 37(3), 2324-2339.

Suzuki, K., Takano, N., Sato, K., 1995. A study of demand forecast model for commuter airlines. Journal of Japan Society of Civ. Eng. 12, 583-594.

Williams, G., Pagliari, R., 2004. A comparative analysis of the application and use of public service obligations in air transport within the EU. Trans. Policy. 11(1), 55-66.

Yamauchi, H., 2000. Toward a more liberal sky in Japan. Deregulation and interdependence in the AsiaPacific Region. NBER-EASE 8(6),195-225. University of Chicago Press.

Yoshida, Y., Fujimoto, H., 2004. Japanese-airport benchmarking with the DEA and endogenous-weight TFP methods: testing the criticism of overinvestment in Japanese regional airport. Transp. Res. E. 40(6), 533546. 
This is the accepted version of an article published by Elsevier in Journal of Air Transport Management made available under Creative Commons CC-BY-NC-ND 4.0 License Available at: http://dx.doi.org/10.1016/j.jairtraman.2016.08.002

Accepted Version downloaded from SOAS Research Online: http://eprints.soas.ac.uk/23066/

\section{Appendix}

Table 2. Assumptions for baseline parameters (Source: NAPC, ANA, Ishikawa Prefecture) Variable name Value

Unit

\begin{tabular}{lcc}
\hline Number of Flights per Day & 4 & Flights/Day \\
\hline Number of Seats per Aircraft & $126(2003), 164(2004), 166(2005-2014)$ & Seats/Fleet \\
\hline Number of Days per Month & 30 & Days/Month \\
\hline Operation Reliability & $0.9936(2003), 0.9957(2004), 0.9950(2005-2014)$ & \\
\hline Fixed Ticket Price & $135(\$ 1 U S D=120 J P Y)$ & USD/Ticket \\
\hline Airport Unit Payment & $135(\$ 1 U S D=120 J P Y)$ & USD/Ticket \\
\hline Airline Unit Payment & $90(\$ 1 U S D=120 J P Y)$ & USD/Ticket \\
\hline Price Adjustment Time & 2 & Month \\
\hline Price Elasticity of Demand & -0.74 (Yamauchi 2000, 195-225) & \\
\hline Load Factor Adjustment Rate & 0 & \\
\hline Demand Adjustment Rate & 0 &
\end{tabular}

Table 3. Monthly passenger demand (NAPC, 2005-2014)

\begin{tabular}{ccccccccccc}
\hline & \multicolumn{10}{c}{ Year } \\
\cline { 2 - 11 } Month & 2005 & 2006 & 2007 & 2008 & 2009 & 2010 & 2011 & 2012 & 2013 & 2014 \\
\hline July & 12,993 & 13,037 & 12,598 & 13,938 & 12,704 & 12,780 & 12,050 & 12,774 & 12,100 & 12,086 \\
\hline Aug. & 16,370 & 16,738 & 15,443 & 14,612 & 14,073 & 14,258 & 15,149 & 15,112 & 15,372 & 15,796 \\
\hline Sep. & 12,252 & 12,141 & 13,809 & 12,853 & 12,405 & 11,420 & 13,222 & 12,807 & 13,988 & 13,345 \\
\hline Oct. & 13,501 & 14,393 & 12,394 & 12,289 & 12,063 & 13,371 & 13,766 & 13,896 & 14,171 & 13,522 \\
\hline Nov. & 13,321 & 13,770 & 13,379 & 11,711 & 11,833 & 12,246 & 13,342 & 14,143 & 13,797 & 13,206 \\
\hline Dec. & 13,418 & 13,054 & 13,587 & 12,384 & 12,244 & 10,047 & 11,680 & 10,581 & 11,242 & 10,072 \\
\hline Jan. & 12,525 & 13,026 & 12,166 & 12,885 & 11,577 & 10,752 & 9,816 & 10,267 & 10,576 & 10,746 \\
\hline Feb. & 11,645 & 12,804 & 11,844 & 11,661 & 11,235 & 10,913 & 10,560 & 11,834 & 8,804 & 9,729 \\
\hline March & 15,511 & 12,776 & 13,288 & 13,443 & 13,209 & 9,348 & 11,314 & 12,851 & 12,657 & 11,782 \\
\hline April & 10,516 & 10,406 & 10,253 & 10,901 & 9,680 & 7,237 & 9,757 & 9,882 & 9,259 & 11,068 \\
\hline May & 14,521 & 11,421 & 14,711 & 12,589 & 13,725 & 10,792 & 12,761 & 13,630 & 13,052 & 13,811 \\
\hline June & 13,920 & 13,016 & 14,906 & 10,811 & 14,418 & 10,162 & 14,564 & 13,437 & 11,827 & 15,419 \\
\hline
\end{tabular}

Table 4. List of fundamental information for foreign market application

Category Information

Population of a target country (with growth rate)

Gross Domestic Production (with growth rate)

\begin{tabular}{|c|c|}
\hline \multirow{10}{*}{ General Information } & \\
\hline & Industrial structure of a target country \\
\hline & Air transportation network and passengers \\
\hline & Highway network and passengers \\
\hline & Highway bus network and passengers \\
\hline & High speed train network and passengers \\
\hline & Naval transport network and passengers \\
\hline & Degree of competition among transportation measures \\
\hline & Seasonality (climate, holiday structure, etc.) \\
\hline & Societal constraints (awareness for environment, natural disaster, labor, etc.) \\
\hline
\end{tabular}


Geographic characteristics

Number of airlines operating in a target country

Degree of competition among airlines operating in a target country

Operation cost structure of a target airline

Operational reliability of a target airline

Number of airway operated by a target airline

Airline $\quad$ Number of flight per day operated by a target airline

Number of flight per day for a target airway operated by a target airline

Number of aircraft owned by a target airline

Variety of aircraft owned by a target airline

Size of aircraft utilized for a target airway

Average ticket price for a target airway

Discount scheme for a target airway offered by a target airline

Number of airports in a target country

Degree of competition among airports in a target country

Airport development plan in a target country

Number of passengers utilizing a target airport

Airport

Operation cost structure of a target airport

Ownership of a target airport

Management structure of a target airport

Financing structure of a target airport

Ground access network to a target airport

Facility of a target airport

General policy for air transportation

Open sky agreement

Government $\quad$ Subsidy policy and program

Tax rates

Management structure

Number of residents

Number of tourists

Local ground transport network

Community $\quad$ Average expenditure by residents

Average expenditure by visitors

Accommodation capacity

Local subsidy programs 


\section{(a) Refereed full papers:}

Tan D \& R Morimoto. 'Tourism and income inequality in developing economies' submitted

Minato N \& R Morimoto, 'Dynamically interdependent business model for airline-airport coexistence' Journal of Air Transport Management, forthcoming

Morimoto R 'Incorporating socio-environmental considerations into project assessment models using Multi Criteria Analysis’, Energy Policy, 2013, 59 (c) 643-653.

Morimoto R 'A 'Smart' future transport infrastructure management system? A socio-economic analysis of Smart Infrastructure sensor technology', Transportation Research Part C, 2013, 31, 18-29.

Okongwu. U, Morimoto. R, Lauras M, 'Maturity levels and framework for studying supply chain sustainability', International Journal of Productivity and Performance Management, 2013, 62 (8).

Minato N \& Morimoto R, 'Collaborative management of regional air transport during natural disasters: Case of the East Japan earthquake and tsunami', Research in Transportation Business \& Management: Special issue on Management of Transport in Remote Regions, 4, 13-21, 2012.

Minato N, Morimoto R, 'Proposing a new management model of regional airport at catastrophic natural disasters: A case of East Japan earthquake and tsunami', Japan Business Model Association Journal, 2012.

Minato N \& Morimoto R 'Designing the commercial sustainability of unprofitable regional airports using system dynamics analysis', Research in Transport Business and Management, vol 1, 80-90, 2011.

Minato N \& Morimoto R 'Policy design for sustainable regional air transport using load factor guarantee’, Japan Journal of System Dynamics, 10, pp. 13-24, 2011.

Minato N \& Morimoto R 'Sustainable airline strategy using portfolio theory: a case study of remote islands in Japan' Journal of Air Transport Management Special Issue: Air Transport and Tourism, 17 (3) 195-198, 2010.

Morimoto $\mathrm{R}$ 'Estimating benefits of effectively and proactively maintaining infrastructure with the innovative Smart Infrastructure sensor system’ Socio-Economic Planning Sciences, 44 (4) 247257, 2010.

Morimoto R \& Agouridas V 'Supporting aircraft manufacturers to systematically formulate and implement sustainability strategies', Transportation Research Record: Journal of the Transportation Research Board, No. 2106, 12-19, 2009.

Morimoto R 'An empirical application of probabilistic CBA: three case studies on dams', International Journal of Sustainable Development \& Planning, 2 (1), 1-18, 2007.

Morimoto R \& Munasinghe M 'Small hydropower projects and sustainable development in Sri Lanka’, International Journal of Global Energy Issues special issue, 24 (1/2), 3-18, 2005.

Morimoto R, Ash J Hope C 'Corporate Social Responsibility: from theory to practice', Journal of Business Ethics 62 (4) 315-325, 2005 (reprint in Magnus Journal of Management, 1 (2), 56-67, 2005).

Morimoto R \& Hope C 'Making the case for developing a silent aircraft' Transport Policy 12(2) 165174, 2005 (selected as Top25 most downloaded article).

Morimoto R \& Hope C 'The impact of electricity supply on economic growth in Sri Lanka', Energy Economics, 26 (1), 77-85, 2004.

Morimoto R \& Hope C 'The CBA model for the Three Gorges Project in China', Impact Assessment and Project Appraisal Journal, 2.2 (3), 205-220, 2004. 
Morimoto R \& Hope C 'An extended CBA model of hydro projects in Sri Lanka', International Journal of Global Energy Issues: special issue on energy and renewable energy with economic development in developing countries, 21 (1/2), 47-64, 2004.

\section{(b) Books/book chapters}

R Morimoto, 'Asian case study: sustainability analysis of the Three Gorges Dam project in China' Chapter 10 in Munasinghe M (ed.), Sustainable Development: new dimensions for business and society, Rio+20 Conference Proceedings, Rio Brazil, June 2012

R Morimoto, 'CSR and hydropower development' book chapter contribution in Adam R/ Timpere (ed.), Corporate Social Responsibility, 165-187, Nova Publishers, US, 2008 (ISBN: 978-160456-284-2).

R Morimoto, 'Corporate Responsibility for Civil Aviation Safety' book chapter contributed in Mary Morimoto, W. Vilcox and Thomas O. Mohan (ed.) Contemporary Issues in Business Ethics, Chapter 6, 135-147, Nova publishers, US, 2007 (ISBN: 1-60021-773-7).

R Morimoto 'Measuring Corporate Responsibility Performance' book chapter contributed in Mary W. Vilcox and Thomas O. Mohan (ed.) Contemporary Issues in Business Ethics, Chapter 7, 149-161, Nova publishers, US, 2007 (ISBN: 1-60021-773-7).

$\mathrm{R}$ Morimoto 'Small hydropower projects and sustainable energy development in Sri Lanka' contributed in Making Development More Sustainable by M Munasinghe, MIND Press, Ch 15, 2007.

R Morimoto 'Three applications of CBA' contributed in Water Resource Management, C Brebbia \& A Kungolos (ed.) 153-162, WIT Press, 2007 (ISBN: 978-1-84564-074-3). 